\title{
La indisolubilidad del matrimonio: su problemática comprensión actual y la importancia de una fundamentación antropológico-jurídica
}

\author{
The Indissolubility of Marriage: Its Problematic Current \\ Understanding and the Importance of an Anthropological- \\ Juridical Foundation
}

Carlos José ERrázuriz M.

Professore Ordinario di Teoria Fondamentale del Diritto Canonico

Pontificia Università della Santa Croce. Facoltà di Diritto Canonico. Roma

errazuriz@pusc.it

Resumen: El artículo se centra en la cuestión de la comprensión de la indisolubilidad matrimonial, como problema de gran importancia práctica de cara a la adecuada aplicación de Mitis ludex y Amoris laetitia. Se procura mostrar que no es posible una adecuada fundamentación de la indisolubilidad del matrimonio si se prescinde del derecho y la justicia. Con ese fin se analizan brevemente algunos modos habituales de argumentar en favor del matrimonio indisoluble (basados en la relación con los bienes del matrimonio, en el papel del amor conyugal y en la sacramentalidad); para luego evidenciar en positivo la substancia del aporte de la visión del matrimonio como relación de justicia a la comprensión de la indisolubilidad.

Palabras clave: Indisolubilidad, Matrimonio, Justicia.
Abstract: This article focuses on the issue of understanding matrimonial indissolubility, a problem of key practical importance for the appropriate application of Mitis ludex and Amoris laetitia. It aims to show that an adequate foundation of the indissolubility of marriage is not possible when justice is ignored. To this end, the article analyzes some of the common arguments in favor of the indissolubility of marriage (the goods of marriage, the role of conjugal love, the sacramentality of marriage) so as to shed positive light on the contribution of the idea of marriage understood as relationship of justice in order to properly understand its indissolubility.

Keywords: Indissolubility, Marriage, Justice. 


\section{Delimitación DEL TEMA}

A 1 aceptar esta ponencia con el título que figura en el programa del Simposio -La indisolubilidad del matrimonio y su problemática actual-, no fui suficientemente consciente de la amplitud y complejidad del tema que se me proponía; si lo hubiera sido, habría sugerido un encabezamiento alternativo restringido que enunciara un objetivo más asequible, como el que ahora he escogido.

En efecto, la centralidad, la amplitud y la actualidad del tema de la indisolubilidad del matrimonio en la vida de las familias, en la Iglesia y en la sociedad civil, saltan a la vista de tal modo que resulta inútil intentar mostrarlas. Pienso que una manera eficaz de expresarlo es decir sencillamente que lo que está en juego en la cuestión de la indisolubilidad es el mismo matrimonio. A mi juicio, habría que redescubrir, en la vida e inseparablemente en la comprensión común y especializada, que el matrimonio o es indisoluble o no es matrimonio.

La actualidad e importancia de esta propiedad esencial de la unión conyugal se ha puesto aún más de relieve en el pontificado de papa Francisco, sobre todo en las dos asambleas del Sínodo de los Obispos por él convocadas, en la reforma del proceso de declaración de la nulidad matrimonial mediante los motu proprio Mitis Iudex y Mitis et Misericors, y en la exhortación pastoral postsinodal Amoris laetitia. No pretendo hacer una crónica de estos años intensos, pero es claro que la indisolubilidad ha estado permanentemente en primer plano. En este sentido, se han replanteado las más diversas cuestiones bíblicas, patrísticas, históricas, magisteriales, teológicas y jurídicas relativas de algún modo a ella ${ }^{1}$; su sola enumeración, que os ahorro por demasiado conocida, asustaría a cualquier ponente que intentara hacer honor al título original de esta ponencia. Sin embargo, a mi entender, existe otro dato más significa-

\footnotetext{
${ }^{1}$ Sigue siendo muy útil el amplio panorama de cuestiones tratadas en el volumen editado en 1978: A. BERNÁRDEZ CANTÓN - T. GARCíA BARBERENA (eds.), El vínculo matrimonial: ¿ divorcio o indisolubilidad?, BAC, Madrid 22015; así como los artículos publicados en Ius Canonicum 11 (1971). De todos modos, en estos años no ha habido tiempo suficiente para grandes novedades en la investigación, y gran parte del debate ha estado más centrado en la admisión a la Comunión eucarística de los fieles divorciados y vueltos a casar civilmente, de manera que la indisolubilidad se toca de modo más bien indirecto, preguntándose si esa admisión es compatible con ella. El título de la reciente traducción italiana del libro de Henri Crouzel indica claramente esta problemática: H. Crouzel, Divorziati «risposati». La prassi della Chiesa primitiva (original francés: 1971), Cantagalli, Siena 2014.
} 
tivo, que tampoco intento demostrar textualmente porque está a los ojos de todos: la tendencia prevalente no ha sido la puesta en tela de juicio de la índole indisoluble del matrimonio, sino que más bien, a comenzar naturalmente por el mismo Santo Padre ${ }^{2}$, se ha manifestado repetidamente el deseo de que la renovación del planteamiento pastoral y jurídico que reclama la presente crisis de la familia, encuentre en el matrimonio la único y verdadera unión entre un hombre y una mujer para siempre, su base inmediata y fundamental. Por consiguiente, la interpretación y aplicación de la nueva ley procesal matrimonial, así como toda la pastoral familiar y el rol decisivo en ella de la misericordia según Amoris laetitia, han de fundarse en una conciencia viva de la palabra de Jesús: «lo que Dios ha unido, que no lo separe el hombre» (Mt 19,6) y en la preocupación eclesial, constante en la historia de la Iglesia, de que esa palabra brille siempre en la vida de los fieles y de las comunidades cristianas.

A la luz de las anteriores consideraciones, he decidido acotar la temática de esta intervención de modo drástico, dedicándola solamente a mostrar hasta qué punto es problemática la comprensión actual de la indisolubilidad, y a evidenciar sumariamente el aporte de luz que puede esperarse del conocimiento del matrimonio como relación de justicia, en lo que cabe llamar una fundamentación antropológico-jurídica, en la línea de esa «antropología jurídica del matrimonio» de que habló Benedicto XVI ${ }^{3}$. Estoy convencido de que por esta vía, que me es connatural por mi dedicación a la filosofía del derecho y a la teoría fundamental del derecho canónico, pueden esperarse frutos duraderos en esa tarea de redescubrimiento del matrimonio que es tal vez un aspecto decisivo en la labor de llevar la Buena Nueva de la familia a la gente de hoy.

Antes de comenzar mi exposición, permítaseme subrayar la convicción de que las cuestiones que tocaré en mis reflexiones no son refinamientos de entendidos que especulan sin preocuparse de lo que realmente pasa en el mundo, sino que, en la medida en que alcanzan a expresar algo de la verdad sobre el designio divino acerca del hombre y la mujer, poseen una gran trascendencia práctica, la cual va mucho más allá de los círculos de la canonística. Los

\footnotetext{
2 Baste recordar los pasajes de la exhortación apostólica postsinodal Amoris laetitia del papa Francisco, 19 marzo 2016, en los que la indisolubilidad del matrimonio es explícitamente reafirmada: cfr. nn. 53, 62, 77, 134, 178.

${ }^{3}$ Cfr. Discurso a la Rota Romana, 27-I-2007.
} 
grandes principios sobre el derecho en la Iglesia son absolutamente necesarios para comprender la misma vida de la Iglesia y de sus hijos en su caminar terreno. En este sentido, es preciso que los canonistas potenciemos nuestra capacidad de dar razón de la juridicidad eclesial de un modo cada vez más comprensible y atractivo, que haga ver el rol insustituible, teórico y practico, de nuestro ser expertos en las relaciones de justicia intraeclesial, haciendo ver que nuestro objeto interesa vitalmente a todos, Pastores y demás fieles, sin olvidar las múltiples instituciones eclesiales, porque las personas y las instituciones son los protagonistas de esas relaciones.

\section{2. ¿POR QUÉ ES PROBLEMÁTICA LA COMPRENSIÓN ACTUAL \\ DE LA INDISOLUBILIDAD DEL MATRIMONIO?}

$\mathrm{Al}$ margen de la cuestión sobre qué conocimiento y aceptación de la indisolubilidad del matrimonio se requiere para que exista realmente un matrimonio, tengo la impresión de que actualmente predomina una clave de lectura que la considera como un bellísimo ideal, que reclama una realización existencial en la relación cotidiana entre los esposos, pero que se encuentra constantemente amenazado por la fragilidad humana. Al fracasar el matrimonio, se piensa que el ideal del «para siempre» ha resultado inalcanzable en el caso concreto. En esas circunstancias el matrimonio, con independencia de que haya o no una causa de nulidad, parece haber dejado de existir realmente, como lo muestran tanto el lenguaje común -que, por ejemplo, acoge sin problemas el concepto de duración del matrimonio, y fácilmente enfoca como excónyuge a quienes han abandonado establemente la vida matrimonial- como las nociones usadas por no pocos canonistas -quienes, por ejemplo, identifican casi siempre el matrimonio in facto esse con la realización existencial del consorcio conyugal, y raras veces lo asocian con el vínculo que permanece-.

$\mathrm{Al}$ romperse de hecho la relación vital, obviamente se advierte que algo queda del matrimonio contraído. No me refiero ahora a los hijos nacidos de él, ni tampoco a los deberes de ayuda mutua que subsisten entre los cónyuges y respecto a la prole. Pienso en el matrimonio en cuanto tal, que parece transformarse en una suerte de ente de razón, de esa razón que se mueve en el mundo de las formalidades jurídicas, o sea del vacío de un derecho positivo separado de la vida. Se trata de un ente que se percibe como carga, ya desde la crisis que ha desembocado en la separación, y que después se busca eliminar incluso de la esfera formal del derecho, para permitir un nuevo enlace. 
En este contexto es oportuno reiterar que la comprensión de la indisolubilidad es una clave decisiva para acceder a la misma idea de matrimonio. Es muy significativo el rechazo tan extendido del término «vínculo» para indicar la relación conyugal ${ }^{4}$, así como la motivación recurrente que lo considera fruto de un enfoque jurídico, o mejor dicho juridicista. Más o menos explícitamente se sostiene que el matrimonio es unión amorosa, no de derecho, por lo que el mismo empleo de categorías jurídicas resultaría perturbador.

Late en estos planteamientos una concepción radicalmente nueva del matrimonio, contrapuesta al patrimonio tradicional de la norma y la doctrina canónicas. Al mismo tiempo, y es lo que más me interesa destacar, opera una visión positivista del derecho, pero ya no de un positivismo que subraya los bienes que son efectos de las leyes emanadas por la autoridad (bienes de los que se reconocía una substancia metapositiva), sino de un positivismo escéptico, que aspira más bien a flexibilizar los preceptos y procedimientos legales de tal modo que ellos no hagan sino reflejar, lo más exacta y rápidamente posible, la situación de las personas y de las comunidades en cada momento de su vida. Pienso que estamos cerca del nihilismo jurídico, del que tanto se habla hoy, y conviene no olvidar que esa cultura puede penetrar en el ámbito jurídico-eclesial mediante la desafección y el relativismo que acompañan a la instrumentalización de las normas y los procedimientos en función de intereses parciales desligados de lo justo.

En esta ocasión, mis reflexiones parten de la hipótesis según la cual no es posible una adecuada fundamentación de la indisolubilidad del matrimonio si se prescinde del derecho y la justicia. Exploro esta hipótesis en dos momentos: en el primero analizo brevemente tres modos habituales de argumentar en favor del matrimonio indisoluble; en el segundo trato de mostrar en positivo la substancia del aporte de la visión jurídica a la comprensión de la indisolubilidad.

Las tres líneas de argumentación que he escogido son: 1) la muy clásica, proveniente sobre todo de la tradición cristiana de pensamiento sobre el derecho natural, la cual se esfuerza en poner de relieve el nexo entre la indisolubilidad y los bienes del matrimonio, teniendo muy especialmente en cuenta el

\footnotetext{
${ }^{4}$ Por lo mismo, resulta tan relevante el uso de la palabra «vínculo» por parte del papa Francisco en Amoris laetitia, en afirmaciones de principio, de ningún modo secundarias, que se refieren a una pastoral y a una espiritualidad del vínculo matrimonial habitado por el amor (cfr. nn. 211 y 315$)$.
} 
bien de la prole, pero también el de los mismos cónyuges y el de toda la sociedad civil y por supuesto el de la Iglesia; 2) la línea más reciente, ligada a diversos enfoques de índole personalista, que subraya la relación entre la indisolubilidad y el amor conyugal; y 3 ) la línea, muy recurrente en la actualidad, que tiende a presentar la indisolubilidad como una consecuencia de la sacramentalidad del matrimonio.

A mi juicio, estos tres planteamientos, entre sí no excluyentes, son muy valiosos, de manera que una visión global de la cuestión no puede dejar de lado ninguno de ellos. A su vez, cada uno de ellos admite múltiples desarrollos, que contribuyen a iluminar la misma realidad desde diversos ángulos. En esta oportunidad no quiero ni exponerlos ni mucho menos criticarlos, sino tan sólo intentar mostrar un límite, común a los tres si se consideran de modo autosuficiente, que dificulta la comprensión del matrimonio como realidad inherente a las mismas personas de modo indisoluble. En mi opinión, ese límite depende, al menos en parte, del hecho de no tener suficientemente en cuenta el aspecto de justicia, o sea intrínsecamente jurídico, de la relación matrimonial, en lo cual influye de modo determinante una concepción insuficiente del derecho, entendido como sistema legal y no como bien objeto de relaciones de justicia.

El primer argumento se basa en los grandes bienes que derivan de la indisolubilidad y en los grandes males que engendra el divorcio, calificado eficazmente por el Concilio Vaticano II como «plaga» ${ }^{5}$. En nuestro tiempo, ante un matrimonio civil con divorcio que pierde cada vez más hasta la apariencia de una relación en principio estable, no pocas personas de buena voluntad, quizá en el pasado partidarias de la introducción de un divorcio restrictivamente reglamentado en las legislaciones civiles, advierten la enorme trascendencia negativa del paso que se llevó entonces a cabo y que se ha demostrado decisivo para conducirnos a la profunda desarticulación legal del matrimonio y la familia, ciertamente con no pequeña influencia en el plano vital.

De hecho hay investigaciones empíricas y estudios sociológicos que muestran de muchos modos el divorcio como mal personal, familiar y social. Se trata de estadísticas e interpretaciones que no deben conducir a la desesperanza ni mucho menos a la falta de misericordia respecto al comportamiento

${ }^{5}$ Cfr. Cost. past. Gaudium et spes, n. $47 \mathrm{~b}$. 
de tantas personas, también bautizadas, en cuanto ellas son también víctimas de carencias graves sobre todo en su educación en el hogar en lo que se refiere al matrimonio y la familia. Sin embargo, no se pueden ignorar los hechos evidenciados por esos estudios, precisamente para redescubrir la grandeza del matrimonio como don ${ }^{6}$.

Razonar en favor de la indisolubilidad desde el punto de vista de los bienes que acarrea es también de gran importancia desde el punto de vista salvífico: para cada uno de los cónyuges el hecho de ser fiel y percibir que el otro lo es en cualquier circunstancia, como parte esencial del camino de fe y de amor de ambos, así como la realidad de que se establezca entre padres e hijos una relación educativa estable y con ambos cónyuges como padres (a menos que no lo permitan circunstancias no imputables a estos últimos), son bienes inestimables para la vida cristiana de los protagonistas y para la vitalidad apostólica de la familia. De este modo, en el reconocimiento y tutela de la indisolubilidad se halla directamente en juego la salus animarum, que paradójicamente los canonistas invocamos con más frecuencia cuando se habla de los casos excepcionales en los que actualmente cabe la disolución eclesial de matrimonios no sacramentales, tema al que aludiré más adelante.

Esta primera argumentación, a pesar de todo su valor, encuentra un límite en las situaciones de fracaso matrimonial, cualquiera sea la culpabilidad de cada uno de los cónyuges. En ese contexto los bienes naturales y sobrenaturales de la unión parecen esfumarse, y en cambio se ponen en primer plano los males de una convivencia infeliz, los bienes de la separación que pone término a una situación considerada insostenible, e incluso, cuando se abandona la convicción de la indisolubilidad, los bienes de una segunda unión, con la búsqueda consiguiente de su reconocimiento como verdadero matrimonio. A mi entender, esta problemática pone de relieve que la fundamentación adecuada del ligamen para siempre no puede situarse en el ámbito de los efectos benéficos del matrimonio, sino que ha de alcanzar el ser mismo del matrimonio. Se trata de pasar de los argumentos de conveniencia sobre aquello que se puede lograr mediante el matrimonio a la indagación sobre lo que el mismo matrimonio es, poniendo el énfasis precisamente en el ser de la unión ${ }^{7}$.

\footnotetext{
${ }^{6}$ La perspectiva del don se encuentra positivamente afirmada en Amoris laetitia, n. 62, citando la Relatio Synodi de 2014, n. 19.

7 Recientemente P.-J. VILADRICH ha expuesto muy lúcidamente esta idea: cfr. I fondamenti antropologici dell'indissolubilità del matrimonio, en H. FrANCESCHI (ed.), Matrimonio e famiglia. La questione antropologica, EDUSC, Roma 2015, 143-216, especialmente 143-155.
} 
Ahora bien, y así entramos en la segunda línea argumentativa, lo que es el matrimonio, y por tanto también su indisolubilidad, tiende hoy a ser captado en la óptica del $a_{m o r}^{8}$, por lo demás tan presente en el magisterio pontificio del último siglo ${ }^{9}$. No cabe duda de que el amor auténtico entre hombre y mujer, que en el matrimonio llega a ser amor conyugal, es fundamental para la captación del matrimonio. Superando la idea de que la existencia del matrimonio depende de que perdure el amor inicial y de que el consentimiento verdadero exija un suplemento de $\operatorname{amor}^{10}$, la verdad es que la separación entre amor y matrimonio no permite entender ni uno ni otro: el amor que un tiempo se llamó libre, esto es desconectado del matrimonio, no es verdadero amor, y el matrimonio sin el específico acto de amor del consentimiento y sin amor conyugal en su realización existencial no puede ser instaurado ni vivido.

Sin embargo, fundar el matrimonio indisoluble en el amor tiene sentido sólo si se piensa en la potencia del amor de Dios que, a través del amor consensual verdaderamente libre de los novios que han hecho posible la acción de esa potencia divina, ha unido a los contrayentes para toda la vida. En cambio, si se argumenta a partir del amor conyugal, dado que éste puede decaer o incluso desaparecer, se puede y se debe concebir la fidelidad para siempre como una exigencia del auténtico amor conyugal, pero no se puede sostener que el vínculo sea indisoluble en cuanto ha de ser vivido por amor. En rigor es verdad lo contrario: el amor para siempre es una exigencia de la indisolubilidad. El discurso sobre el amor conyugal necesita ser completado por la consideración del matrimonio; en este sentido, es muy significativo que la Gaudium et spes haya hecho algunas afirmaciones con un sujeto doble: el matrimonio y el amor conyugal ${ }^{11}$. Es la misma distinción expresada por Amoris laetitia, al hablar de «vínculo habitado por el amor divino» ${ }^{12}$.

${ }^{8}$ Cfr. por ejemplo una exposición muy lograda: J. J. PÉREZ-SOBA, El amor crea vínculos: un anuncio liberador, Revista Española de Teología 75 (2015) 141-171.

9 Es una constante desde la encíclica Casti Connubii di Pio XI, hasta la exhortación Amoris laetitia del papa Francisco, en la que el amor da al documento el incipit y el tema («sobre el amor en la familia»), pasando por el Concilio Vaticano II en la Constitución pastoral Gaudium et spes, nn. 46-52, el magisterio posterior, como la encíclica Humanae vitae del Beato Pablo VI, nn. 8-9 y el amplísimo y profundo magisterio de San Juan Pablo II sobre el matrimonio y la familia.

10 Contra esta idea se pronunció el Beato Pablo VI en un célebre Discurso a la Rota Romana, del 9-II-1976.

${ }^{11}$ Cfr. nn. 48a y 50a.

${ }^{12}$ N. 315. 
En suma, el problema para basar la comprensión del matrimonio indisoluble sobre el amor que se deben marido y mujer proviene simplemente del hecho de que el amor humano, tanto en su aspecto natural como sobrenatural, no es indisoluble. El vínculo conyugal, fundado como dijimos en la acción conjunta del amor divino y humano, es ciertamente un vínculo de amor, pero, sin olvidar nunca la fidelidad incondicional del amor de Dios, por desgracia no siempre hay amor actual entre los cónyuges, sino tan sólo amor debido. Se me perdone lo obvio de estas consideraciones, que sólo pretenden hacer ver que falta algo para entender la indisolubilidad. No estamos más que ante un caso especialmente relevante de la problemática tendencia tan extendida en la Iglesia a plantear todas las cuestiones prácticas en el plano exclusivo del amor. Se olvida que la caridad es ciertamente forma de todas las virtudes, según la famosa expresión de Santo Tomás de Aquino ${ }^{13}$, pero no como si las demás virtudes consistieran esencialmente en el amor, siendo por tanto absorbidas e incluso eliminadas por él, sino en cuanto la caridad las ordena al último fin, dándoles por tanto el sentido último, lo que implica confirmarlas y reforzarlas, no quitarlas ni minusvalorarlas.

Llegamos a la tercera línea de razonamiento fundante de la indisolubilidad, muy extendida en nuestros días en la comprensión eclesial, tanto común como de especialistas. Se suele afirmar o presuponer que el matrimonio es verdaderamente indisoluble en cuanto es un sacramento de la Nueva Alianza, y por tanto participa del carácter irrevocable de la unión entre Cristo y su Iglesia. Esta convicción se halla estrechamente ligada al hecho de que en la Iglesia sólo es absolutamente indisoluble el matrimonio rato y consumado. En efecto, la praxis de los Romanos Pontífices reconoce la disolución tanto de los matrimonios no sacramentales, ya sean consumados o no, así como de los matrimonios sacramentales no consumados. Se puede ciertamente afirmar con verdad que estas uniones son intrínsecamente indisolubles, porque para que opere la disolución se requiere siempre una intervención de la potestad pontificia. Mas al fin lo que cuenta es el hecho de que exista o no una vía por la que, a pesar de subsistir un matrimonio válido, una de las partes pueda celebrar un nuevo pacto conyugal válido. Por esta razón, la indisolubilidad de los matrimonios que no son sacramentales y consumados es vista como una afirmación teórica, más pertinente para

${ }^{13}$ Cfr. Summa theologiae, II-II, q. 24, a. 8. 
oponerse al divorcio en los ordenamientos civiles que para concebir la disciplina intraeclesial.

No cabe duda de que este tercer tipo de razonamiento presenta una ventaja importante respecto de los dos anteriores: el matrimonio rato y consumado es completamente indisoluble también en el seno de la Iglesia, y lo es no por razones de especial conveniencia o de servicio al bien de las almas (que sirven para justificar la posible disolución de los demás matrimonios), ni tampoco por exigencias singulares del amor mutuo entre cristianos, sino por una razón teológica: el ser mismo del matrimonio de los bautizados ha alcanzado su perfección constitutiva mediante el primer acto conyugal. De este modo, la propiedad de la indisolubilidad, confirmada por la sacramentalidad, que a su vez llega a plenitud en la consumación, al asumir un carácter absoluto, como realidad indisponible incluso para la autoridad suprema de la Iglesia, se revela como una dimensión intrínseca del ser del matrimonio rato y consumado. $\mathrm{Al}$ menos este matrimonio es en cualquier caso indisoluble.

Sin embargo, esta fundamentación sacramental no consigue integrar adecuadamente la indisolubilidad existente en el plano natural o creacional, por lo demás tan decisiva en los textos evangélicos que remiten al principio ${ }^{14}$. En efecto, tengo la impresión de que falta una percepción más clara del mismo signo sacramental del matrimonio, que sigue siendo visto de modo más bien extrínseco. Sin entrar en esta tan debatida cuestión, me parece que se cae muchas veces en una dicotomía perturbadora: por un lado, el matrimonio natural, que en rigor es tan poco real como la naturaleza humana pura (lo que existe es la dimensión natural de todo matrimonio), que tiende a verse como realidad profana e inmanente; por otro lado, el matrimonio sacramental, ciertamente religioso y trascendente, pero del que no se pone suficientemente de relieve su profunda conexión con la una sola carne del principio, y más bien se conecta con una acción o intencionalidad añadida de los contrayentes o del ministro. A los efectos que aquí nos interesan, no sólo se parte siempre de la reducción del ámbito de los matrimonios absolutamente indisolubles a los que son ratos (sacramentales) y consumados, sino que incluso esta indisolubilidad parece más efecto de una tradición puramente disciplinar, no obstante los pronunciamientos del magisterio supremo que llegan a considerarla una verdad definitiva-

${ }^{14}$ Cfr. Mt 18,4 y 8; Mc 10,6. 
mente enseñada ${ }^{15}$, por lo que no pocas veces reaparece la idea de extender la potestad papal de disolución a los matrimonios ratos y consumados. A mi juicio, esto confirma que debe profundizarse la misma indisolubilidad de cualquier matrimonio ${ }^{16}$. De otro modo, el conjunto de la actual disciplina eclesial corre el peligro de ser visto como fruto de compromisos contingentes que al final podrían conducir simplemente a incorporar el divorcio en la Iglesia.

\section{LA INDISOLUBILIDAD EN EL CONTEXTO DE LA COMPRENSIÓN DE LA DIMENSIÓN DE JUSTICIA INHERENTE AL MATRIMONIO \\ COMO UNA SOLA CARNE}

Exponer en positivo la convicción según la cual para comprender la propiedad de la indisolubilidad, y en definitiva para entender la esencia del matrimonio, es necesario adoptar una visión jurídica, es decir de justicia, es tarea ciertamente ambiciosa. En esta sede, que es justamente donde he aprendido tanto sobre esta perspectiva ya desde mis estudios de licenciatura en derecho canónico ${ }^{17}$, siento además la tentación de callar, dando por sabido todo lo que

${ }^{15}$ Cfr. el Discurso a la Rota Romana del 21-I-2000, en el cual SAn Juan Pablo II afirmó: «se deduce claramente que el Magisterio de la Iglesia enseña la no extensión de la potestad del Romano Pontífice a los matrimonios sacramentales ratos y consumados como doctrina que se ha de considerar definitiva, aunque no haya sido declarada de forma solemne mediante un acto de definición» (n. 8).

16 Resulta de gran importancia compatibilizar las afirmaciones del magisterio eclesiástico sobre la indisolubilidad que se refieren a cualquier matrimonio, con la praxis de la misma Iglesia que, en algunos casos, todo lo limitados que se quiera, hace excepciones a esa propiedad esencial. Algunos estudiosos, partiendo de investigaciones históricas rigurosas y conservando el más total obsequio al magisterio eclesiástico, se han dedicado recientemente al estudio de la fundamentación teológica y jurídica de los diversos supuestos de disolución. Sobre la disolución del matrimonio rato no consumado, cfr. por ejemplo J. SEDANO, Las incertidumbres históricas sobre la potestad pontificia de disolver un matrimonio rato y no consumado: una clave interpretativa de la formación del vínculo matrimonial, Ius Canonicum 56 (2016) 229-269. Sobre la disolución del matrimonio no sacramental en virtud del privilegio de la fe, cfr. entre otros D. GARCía HerVÁs, La disolución del matrimonio «in favorem fidei»: elementos para una investigación, Pontificia Universidad de Salamanca, Salamanca 2008; N. ÁlvareZ DE las Asturias - M. PARMa - J. C. Conde - F. MARTi, Studi sul favor fidei, Ius Ecclesiae 26 (2014) 311-378.

17 Tengo muy grabado cómo nuestro profesor de Derecho Matrimonial Canónico en el curso 1980-1981, el gran matrimonialista Pedro-Juan Viladrich, se esforzaba en hacernos captar desde el comienzo que el matrimonio no es el simple hecho empírico de cohabitar. Luego me han ayudado mucho sus copiosos y profundos escritos, como por ejemplo el reciente que he citado en nota 7. Aunque nunca fui alumno directo del Prof. Javier Hervada en temas matrimoniales, tampoco en la investigación doctoral, su lectura me ha sido siempre muy iluminadora. Con una profundidad y rotundidad singulares ha ido penetrando en lo que es el matrimonio y en todos sus aspectos como un verdadero clásico, tan presente en las elaboraciones del mismo Viladrich 
diré. No caigo en ella porque tengo la impresión de que tanto para canonistas y juristas civiles como para cultores de otras disciplinas que se ocupan del matrimonio, una visión verdaderamente jurídica del matrimonio sigue casi siempre ausente, sustituida no pocas veces por una superestructura formal que sirve para prevenir y resolver situaciones problemáticas en el campo del matrimonio y la familia. No tengo aquí ninguna pretensión de originalidad respecto a mis maestros y colegas. Es más, trataré sobre todo de exponer ordenadamente algunos aspectos fundamentales de los que ellos tratan, tal vez con algún matiz nuevo, como el relativo a la misma noción de derecho entendido como lo justo. $\mathrm{Y}$ hablaré poco de indisolubilidad, porque creo que ella es incomprensible si no se la sitúa en el contexto de la esencia del matrimonio ${ }^{18}$.

Para comprender el matrimonio y su dimensión jurídica la revelación bíblica nos ofrece un punto de partida verdaderamente esencial en su simplicidad: el matrimonio como una sola carne (una caro). La búsqueda de la razón, sostenida por la fe, debe examinar el significado de esta expresión, referente al verdadero matrimonio como realidad experiencial universal.

«¿No han leído ustedes que el Creador, desde el principio, los hizo varón y mujer; y que dijo: Por eso, el bombre dejará a su padre y a su madre para unirse a su mujer, y los dos no serán sino una sola carne? De manera que ya no son dos, sino una sola carne. Que el hombre no separe lo que Dios ha unido» ${ }^{19}$. Estas breves palabras de Jesús confirman la revelación veterotestamentaria y muestran su profundidad y sus consecuencias. Trataré de evidenciar la dimensión de derecho, y por ende de justicia, que está implícita en esta enseñanza evangélica ${ }^{20}$.

Los cónyuges se hacen una sola carne mediante el acto conyugal que les une y es de suyo idóneo para la generación de la prole. Este primer significado

y de tantos otros matrimonialistas, también colegas míos. De Hervada resulta imprescindible la colección de escritos llamada Una caro. Escritos sobre el matrimonio, Eunsa-Instituto de Ciencias para la Familia, Pamplona 2000. Profundiza especialmente en la óptica que hoy me ocupa J. I. BAÑARES, La dimensión conyugal de la persona: de la antropología al derecho, Rialp, Madrid 2005. También en esa perspectiva antropológico-jurídica, cfr. H. FrANCESCHI, La indisolubilidad del matrimonio. ¿Por qué para siempre?, en C. MENDOZA (ed.), Perspectivas de cultura cristiana, Il pozzo di Giacobbe, Trapani 2014, 89-114.

${ }^{18}$ Una presentación del debate canonístico en el siglo XX se encuentra en F. PUIG, La esencia del matrimonio a la luz del realismo jurídico, Navarra Gráfica Ediciones, Pamplona 2004.

${ }^{19}$ Mt 19,4-6; cfr. Gen 1,27.

20 Sigo en sus líneas esenciales la interpretación de la una caro como unidad en las naturalezas (o como dice a veces, en la naturaleza), propuesta por mi maestro Javier Hervada. Pienso que esta perspectiva se ilumina todavía más cuando se conecta con la idea de derecho como objeto de la justicia, cuya centralidad ha sido percibida por el mismo Hervada en un momento posterior. 
de la una sola carne, expresamente recordado por el canon $1061 \$ 1$ del Código del 1983, es indudablemente muy iluminante, en cuanto permite identificar inequívocamente la especificidad del matrimonio, ordenado por su naturaleza a ese acto. Cualquier comprensión de la unión matrimonial que oscureciese esta ordenación a ser una sola carne mediante la cópula conyugal, no acogería la esencia del matrimonio. Sin embargo, es muy importante no reducir el ser una sola carne a los actos conyugales. Al presentar Jesús la unidad de los cónyuges como una realidad que Dios ha unido y que el hombre no debe separar, es claro que la noción de la una sola carne no se limita a ciertos actos, sino que se refiere a la unión permanente entre hombre y mujer. $\mathrm{Al}$ mismo tiempo, esta ampliación analógica de significado evidencia que marido y mujer al ser uno en el matrimonio se encuentran ligados precisamente en la carne. Para comprender el sentido bíblico de la carne, que a partir del cuerpo designa la entera naturaleza humana, conviene tener presente el misterio de la encarnación del Verbo, que se refiere a la asunción unitaria de aquella naturaleza, tanto en el cuerpo como en el alma. La dimensión corporal es ciertamente esencial en el matrimonio, y solamente a partir de ella se puede comprender la unión conyugal. Pero la dimensión espiritual es igualmente esencial, porque de lo contrario no se acoge la humanidad del matrimonio. Al mismo tiempo, la referencia bíblica a la carne aleja cualquier concepción dualista del hombre, opuesta a la radical unidad espíritu-materia que caracteriza la una sola carne.

¿Cómo es posible que el hombre y la mujer se unan tan profundamente? El modelo del intercambio de los derechos resalta la autonomía de la persona, que no viene negada ni disminuida por el matrimonio. Marido y mujer, en efecto, continúan siendo personas distintas, cada una dotada de dignidad, libertad y responsabilidad personales también en el ámbito de su relación conyugal. En esto aquel modelo tiene razón, pero resulta insuficiente porque coloca la unión en el ámbito de las prestaciones que son objeto de derechos y de deberes conyugales, como si la unión se situase esencialmente en el plano del actuar común para lograr determinadas finalidades. En cambio, la noción de una caro en sintonía con la percepción del sentido común, sitúa el matrimonio en el plano del ser, que se manifiesta en el actuar pero no se puede reducir a él. Se actúa como cónyuge porque se es cónyuge, y la inversión de este orden contradiría la esencia misma de la unidad entre los esposos. Se introduciría una lógica contractualista de la unión, que no daría razón del ser marido y mujer como identidad personal correlativa. De ahí que incluso una fundamentación tan noble como la que se apoya en el carácter de compromiso o prome- 
sa irrevocable que es propio del matrimonio, resulte insuficiente si no se aclara por qué en este caso no existen razones que justifiquen esa irrevocabilidad. Los compromisos más solemnes pueden ser legítimamente revocados en la medida en que cambia la situación real en la que se formularon, de manera que las prestaciones originales que fueron pactadas como derechos mutuos dejan de tener sentido; en cambio, la indisolubilidad matrimonial significa que nunca se da esa mutación real, por más que todas las expectativas de la boda, verdadera boda, hayan fracasado.

Ante la dificultad de fundar el matrimonio para toda la vida en el plano del solo obrar debido, resulta natural pensar en la solución ofrecida por el modelo alternativo de la integración interpersonal existencial. En efecto, parece que ese modelo pone en el centro las personas del hombre y de la mujer, exaltando su unidad precisamente en cuanto personas, hasta el punto de que a veces se imagina una especie de fusión existencial. La lógica de las prestaciones recíprocas cedería a la lógica personalista, de total donación-aceptación. La dificultad de este enfoque deriva del hecho que tiende a moverse en un plano exclusivamente existencial, que en el fondo no aclara en qué consiste la unidad permanente entre hombre y mujer. La integración entre las personas es de por sí vital, dinámica y ciertamente representa una exigencia del matrimonio, pero es bien diverso sostener que ella sea la esencia del matrimonio. Tan pronto como se afirma esto, se advierte el peligro de considerar que la duración de la unión dependería de la perseverancia de las partes en su amor, y con esto desaparece la una caro.

Las palabras del Génesis citadas por Jesús, en su simplicidad, nos indican una vía segura para profundizar el sentido de la una sola carne. Ellas hablan en efecto del ser creados desde el principio varón y mujer. El dejar el hombre al padre y a la madre y unirse a su mujer aparecen como consecuencias del ser varón y mujer. Esto es ciertamente obvio, pero corresponde a una verdad antropológica que está en la raíz de la comprensión esencial del matrimonio. El hombre y la mujer se casan precisamente en cuanto hombre y mujer, según la mutua relación inherente a tal identidad. La unión entre ellos es natural en el sentido de que se refiere a la dimensión natural de la respectiva masculinidad y feminidad. Esta índole natural, remarcada por el magisterio pontificio reciente $^{21}$, debe ser entendida según la comprensión metafísica que el mismo

${ }^{21}$ Cfr. sobre todo San Juan Pablo II, Discurso a la Rota Romana, $1^{\circ}$ febrero 2001. 
magisterio da al concepto de naturaleza, es decir esencia como principio de operaciones. Esta comprensión supera cualquier visión reductiva de lo natural, como si se contrapusiera a lo humano: hay una naturaleza humana, propia de la persona humana, de modo que ser hombre o mujer son modalidades inherentes al ser natural de la persona humana. De este modo es reconocido y valorizado el sentido propiamente humano y personal de la sexualidad y su intrínseca unión con la libertad y la razón de la persona, así como con su capacidad de amar y de comprometerse. Al mismo tiempo, la concepción auténticamente personalista del matrimonio presupone su radicación en la dimensión natural del ser hombre y mujer, fuera de la cual es imposible aferrar en qué consiste lo que es matrimonial ${ }^{22}$.

La índole natural de la distinción sexual se ilumina ulteriormente cuando se considera la intrínseca relacionalidad de esa realidad ${ }^{23}$. Ser hombre y ser mujer constituyen modalidades diversas y complementarias de la misma naturaleza humana, y su unión es fruto de una inclinación natural, libre y responsablemente seguida. El matrimonio actualiza lo que en la naturaleza del hombre y de la mujer está en potencia, lo cual constituye una realidad vocacional para la gran mayoría de la humanidad. Esto no significa que el casarse constituya la única vía a través de la cual vivir el ser hombre y mujer, porque la relacionalidad inherente a estas dimensiones admite otras realizaciones, entre las cuales posee un valor único en el orden salvífico el celibato por el reino de los cielos. Pero es indudable que en la unión matrimonial la complementariedad relacional hombre-mujer muestra su primordial sentido natural. Por otra parte, tal sentido es de carácter dinámico, como es propio de la misma idea de naturaleza, por lo cual la consideración de los fines del matrimonio, tanto el bien de los mismos cónyuges como la procreación y la educación de los hijos, resulta fundamental para comprender su esencia, la cual se encuentra constitutivamente ordenada a esos fines naturales.

La auténtica relacionalidad del ser hombre o mujer, que se manifiesta de tantos modos enriquecedores en todas las esferas de la vida humana, encuentra su actualización específica en la una sola carne. La inclinación o tendencia

${ }^{22}$ Sobre la visión personalista del matrimonio y sobre su relación con el derecho, cfr. SAN JUAN Pablo II, Discurso a la Rota Romana, 27 enero 1997.

${ }^{23}$ Una filosofía de la familia en la óptica relacional del derecho ha sido presentada por F. D’AGOSTINO, Filosofía de la familia, trad. cast., Rialp-Instituto de Ciencias para la Familia-Universidad de Navarra, Madrid-Pamplona 2006. Una sociología de la familia en clave relacional se encuentra en P. Donati, Manual de sociología de la familia, trad. cast., Eunsa, Pamplona 2003. 
hacia la persona del otro sexo, lleva consigo, mediante el evento del pacto conyugal, a una relación concreta, entre un hombre y una mujer, en la cual se unen plenamente las potencialidades naturales inherentes a estas identidades personales. Esto es posible gracias al hecho de que la condición masculina y la condición femenina, de por sí relacionales, existen en la realidad de la naturaleza de las personas humanas, pero se necesita también el acto libre y conjunto del hombre y de la mujer que se dan y se aceptan en cuanto cónyuges. La unión es fruto de su libertad, pero su configuración esencial no es modelada por tal libertad, y no subsiste en virtud de una perseverancia del libre consentimiento. La una caro supera las posibilidades inventivas y operativas de los contrayentes, porque se basa en lo profundo de la naturaleza relacional hombre-mujer. Ellos ciertamente dan vida a su unión, pero ésta no se funda esencialmente sobre ningún factor escogido y preferido por ellos. El matrimonio no es unidad en ninguna cualidad de los cónyuges, por más noble y determinante que sea en la decisión de casarse. La unidad del matrimonio se refiere a la masculinidad y la feminidad en cuanto dimensiones naturales, diversas y complementarias, del ser persona humana.

Pero ¿en qué consiste la unión natural entre el hombre y la mujer en cuanto tales? ¿Cómo los dos logran ser uno? Ciertamente no se trata de una fusión ontológica, porque las dos personas no pueden perder la incomunicabilidad propia de su ser personal, y por tanto la intransferible dignidad, libertad y responsabilidad de cada una también en su relación como cónyuge. La cuestión se refiere precisamente a la determinación del modo de comunicarse, y por tanto de poner en común el ser masculino y el ser femenino. Ante todo, debe tenerse presente que la masculinidad y la feminidad son relacionales, por lo que, presupuesta la vocación y la decisión matrimonial, están de por sí orientadas a entrar en comunión, tanto en el cuerpo como en el alma. Como modo de comunicar la masculinidad y la feminidad, es fácil pensar en el amor que une a los esposos, aquel amor tan ligado al matrimonio que se llama conyugal o matrimonial. San Pablo expresa el nexo entre el amor y la una caro con gran eficacia: «Del mismo modo, los maridos deben amar a su mujer como a su propio cuerpo. El que ama a su esposa se ama a sí mismo» (Ef 5,28$)$. Dice que «deben amar», y que el fundamento de tal deber reside en la profunda unidad que se ha establecido entre marido y mujer. A esta unidad, que abarca tanto el cuerpo como el alma, se refiere el mismo Pablo a propósito del acto conyugal: «Que el marido cumpla los deberes conyugales con su esposa; de la misma manera, la esposa con su marido. La mujer no es dueña de su cuerpo, 
sino el marido; tampoco el marido es dueño de su cuerpo, sino la mujer» (1 Cor 7,3-4). Estos textos evidencian que el vínculo conyugal tiene una esencial dimensión de justicia, en virtud de la cual el hombre y la mujer se pertenecen mutuamente y son de verdad el uno para el otro «mi mujer»y «mi marido», de una manera permanente que sobrepasa el ámbito del actuar juntos. Dado que la relación se refiere a un aspecto tan personal como el ser hombre o mujer, ella solamente puede ser vivida mediante el amor mutuo interpersonal. Pero este amor es debido, no ya en el sentido por el cual se debe amar a toda persona humana en cuanto prójimo, sino según las exigencias específicas del vínculo conyugal. $\mathrm{Y}$ tales exigencias entran en el ámbito de la justicia, porque presuponen una unión peculiar entre el hombre y la mujer, en virtud de la cual cada uno de ellos es del otro.

Para comprender mejor este vínculo de justicia, se necesita determinar el derecho que lo funda. Si entendemos por derecho el bien de una persona en cuanto le es debido por otro ${ }^{24}$, es fundamental determinar cuál es ese bien en el matrimonio. Se podría pensar que la misma persona humana de los esposos, en la totalidad de su ser relacional, constituye el bien conyugal, es decir, que los cónyuges son derecho el uno para el otro según una plenitud de vida que debe ser compartida. Este planteamiento presenta al menos dos problemas: la misma persona no puede constituir un derecho, un bien jurídico perteneciente a otro, ya que esto contradiría su incomunicabilidad; y el supuesto bien jurídico tendría una extensión amplia e indeterminada como la vida de las personas en su relacionalidad. Por otra parte, el bien matrimonial no puede reducirse a un conjunto de prestaciones mutuas, las cuales no explicarían la permanencia de la unión y darían lugar también a problemas sobre su determinación concreta, en la medida en que tales prestaciones dependen de las circunstancias de cada situación. Descartadas estas dos respuestas, se comprende mejor el sentido de la afirmación según la cual el bien en la unión conyugal está constituido por la misma relación entre la masculinidad y la feminidad de las personas casadas. Esta tesis, que podría parecer tautológica, encierra en cambio a mi juicio una comprensión realista y profunda del matrimonio, muy en línea con la noción de la una sola carne. Trataré de analizarla brevemente y de mostrar su congruencia con la indisolubilidad matrimonial.

${ }^{24}$ Este sentido tradicional del derecho como lo justo, o sea como objeto de la justicia, presente en Aristóteles y Santo Tomás y en los juristas romanos, ha sido vigorosamente repropuesto en el siglo XX por diversos autores, entre los que sobresalen Michel Villey y Javier Hervada. 
Desde el punto de vista del derecho, la masculinidad es ante todo un bien del mismo hombre, así como la feminidad pertenece a la misma mujer. Se trata de bienes naturales inherentes a las mismas personas humanas, cuya juridicidad depende de la existencia de deberes de justicia por parte de los demás y de la misma sociedad, ante todo el respeto socialmente debido a la condición masculina y femenina. Para comprender la índole esencial de tales deberes de justicia, se debe recordar que la masculinidad y la feminidad son bienes relacionales, en cuanto sitúan de suyo a la persona en una determinada relación con los demás. Esta relación conlleva sobre todo la inclinación natural a la unión con una persona del otro sexo. Cuando se da la unión como fruto del concurso de la naturaleza y de la libertad, se verifica algo único en el mundo humano: bienes naturales inherentes a dos personas, la masculinidad y la feminidad, en su relacionalidad específicamente conyugal, pasan a constituir verdaderos derechos del otro. La masculinidad del hombre en cuanto unido a la mujer se hace un bien de ésta, en cuanto le pertenece y le es debida en justicia por parte de su marido. Al mismo tiempo, como aspecto inseparable de una única unión, la feminidad de la mujer en cuanto ligada al hombre pasa a ser un derecho de este último, un bien suyo que le es debido por parte de la mujer. De este modo hay una verdadera comunicación y mutua participación entre marido y mujer, la cual en su esencia es jurídica, porque implica los dos presupuestos esenciales del derecho: la configuración de un bien como propio de una persona y la dependencia de la efectividad de tal pertenencia del actuar de los otros. El matrimonio y la familia en él fundada, resultan así naturalmente determinados, con una determinación esencial que es garantía de auténtica vitalidad.

«De manera que ya no son dos, sino una sola carne. Que el hombre no separe lo que Dios ha unido» (Mt 19,6). La primera consecuencia que Jesús saca de la verdad del principio sobre la una sola carne, se refiere a la indisolubilidad. Esto se explica obviamente en el contexto del diálogo con los fariseos, cuyo tema era precisamente la posibilidad del repudio. Pero pienso que para la misma comprensión de la una sola carne, la propiedad esencial de la indisolubilidad es completamente decisiva. La unión entre el hombre y la mujer no alcanza su plenitud si no compromete la totalidad también temporal de su masculinidad y feminidad. La comunicación y la coparticipación del ser masculino y femenino es inauténtica si está amenazada por la caducidad mientras los cónyuges viven. Una donación parcial de estas dimensiones no sólo es injusta, de una injusticia que no desaparece en virtud del recíproco consenti- 
miento, sino que en realidad no puede ser matrimonial, en cuanto contradice el hecho que el hombre y la mujer casados, en cuanto tales, no son ya dos. De este modo, se entiende adecuadamente la totalidad de la unión, refiriéndola sólo a la conyugalidad, y se evita concebirla como una fusión existencial que abarcaría todas las dimensiones de la vida de los contrayentes, fusión de hecho imposible y por eso apta para presentar todo fracaso como nulidad.

Es fácil admitir, sobre la base de la fenomenología del amor humano, que la indisolubilidad es un ideal bello. La dificultad nace cuando por causas voluntarias o involuntarias, la vida matrimonial ya no existe. Es entonces cuando el vínculo puede aparecer como una realidad vacía, que existiría únicamente en un registro y en la aplicación de una ley positiva. No obstante, es justamente en tales circunstancias cuando resuenan con toda su fuerza las palabras de Jesús: «Que el hombre no separe lo que Dios ha unido», con su llamada a la reconciliación de los cónyuges y por lo tanto al mutuo respeto de su identidad relacional, teniendo en cuenta toda su relevancia para ellos mismos, para los hijos y para la sociedad. La una caro no ha sido el mero producto de la voluntad humana: es Dios mismo, creador del hombre y de la mujer, de su relacionalidad natural, quien ha unido su ser masculino y femenino en matrimonio. Y el para siempre pertenece a la configuración natural de tal unión, a su estructura jurídica esencial. Se permanece marido y mujer también cuando parece haber muy buenas razones para disolver tal enlace, cuando por motivos -justificados o no- se ha instaurado una separación, o cuando se ha buscado establecer una nueva unión. Es innegable que en este vínculo de justicia que resta intacto en cualquier circunstancia se descubre un misterio, que se ilumina en el contexto del plano salvífico de Dios para la humanidad en Cristo (cfr. especialmente Ef 5,21-33), pero no ha de olvidarse que la iluminación mediante la fe presupone el diseño natural, creacional, del principio. En el acoger la indisolubilidad de la una sola carne, se toma con absoluta seriedad el ser relacional según justicia de la unión entre hombre y mujer.

$\mathrm{Al}$ poner de relieve la dimensión de justicia del matrimonio no se obscurece o atenúa la relevancia del amor conyugal. Es la misma dinámica del amor la que presupone y se funde con la dinámica de la justicia. En efecto, el amor conyugal es verdadero si mueve a actualizar lo que es justo en las relaciones entre marido y mujer, conformándose siempre a la conyugalidad de ambos, es decir a la relación de mutua pertenencia en la masculinidad y feminidad. A su vez ser justos en la relación conyugal requiere el amor, porque los actos externos que se deben recíprocamente los cónyuges sólo pueden ser realizados de 
modo matrimonialmente justo si hay amor. Amor y justicia se entrelazan profundamente en este ámbito: el amor indica el horizonte interpersonal de la unión y la plenitud a la que está destinada; la justicia corresponde a la estructura fundamental de la unión según la naturaleza, en la cual el hombre y la mujer, permaneciendo autónomos entre sí, son realmente derecho-bien justo del otro en lo que se refiere a su dimensión conyugal (es el sentido profundo del ser «mi marido»y «mi mujer»). Se puede decir que la justicia es prioritaria desde el punto de vista del fundamento, ya que la especificidad jurídica de la relación con el otro funda las exigencias de la verdad del amor conyugal, y que en cambio el amor es prioritario desde el punto de vista vital, pues empuja a vivir según el derecho y a ir más allá de él. Por tanto, no hay por qué temer que una fundamentación antropológico-jurídica de la indisolubilidad pueda suponer un retroceso en la comprensión del matrimonio, a una etapa juridicista que olvidaba el amor. El peligro es más bien el opuesto: que la exaltación pretendidamente personalista del amor acabe por perder de vista la esencia del matrimonio y por eso mismo del amor matrimonial y de la misma persona en su naturaleza humana.

Con este planteamiento de justicia tampoco se deja de lado o se minusvalora la perspectiva salvífico-sacramental. El tema es ciertamente vasto y difícil, pero puede bastar aquí una observación muy sencilla. No cabe contraponer una adecuada consideración antropológico-jurídica con una consideración religiosa del matrimonio, por la sencilla razón de que esta última presupone la primera. Cuando San Pablo afirma que «gran misterio es éste, pero yo lo digo en relación a Cristo y a la Iglesia» (Ef 5,32), se está refiriendo a la realidad considerada en el versículo precedente, que se mueve inequívocamente en el plano de la creación: «Por esto dejará el hombre a su padre y a su madre y se unirá a su mujer, y serán los dos una sola carne» (Ef 5,31, citando Gen 2,24). De ahí que una fundamentación antropológico-jurídica de la indisolubilidad sea la base indispensable de una fundamentación salvífico-sacramental. Despojada de su aspecto de justicia, cualquier profundización en el gran misterio de la unión conyugal corre el serio riesgo de olvidar la misma consistencia de ese misterio, es decir, en qué consiste el respectivo signo y causa sacramental, lo que comporta un vaciamiento del mismo sacramento, reducido a ritos o intenciones humanas, que al ser extrínsecos respecto a la esencia del matrimonio, no pueden explicar el reforzamiento sobrenatural de la indisolubilidad. En efecto, la indisolubilidad sólo puede ser potenciada si existe realmente en el plano de la naturaleza humana. 


\section{A MODO DE CONCLUSIÓN}

Podría parecer que todo lo expuesto es, como se suele decir, «poco jurídico», esto es «poco práctico» de cara a las tareas que compete llevar a cabo habitualmente a los canonistas. Se trataría de una disertación más o menos convincente, pero en todo caso más bien fuera de lugar.

Para «defenderme» yo haría notar que constantemente he hablado de justicia y de derecho. Es verdad que me he movido en el plano de la comprensión del matrimonio indisoluble, no en el ámbito de las múltiples consecuencias operativas que de ahí se siguen. Lo he hecho porque estoy convencido de que el más grave problema práctico -en todas sus vertientes: moral, jurídica, pastoral, etc.- con el que nos enfrentamos cotidianamente en este ámbito se refiere precisamente a la comprensión de lo que es el matrimonio. Y paradójicamente, somos nosotros los juristas, muy a menudo injustamente identificados como expertos en «deshacer» matrimonios, los que, por nuestra misma mentalidad jurídica entendida en toda su nobleza, estamos más en condiciones da aportar una visión que recupere la dimensión de justicia, integrándola armónicamente con toda la riqueza vital del matrimonio y la familia.

Confieso que querría mostrar cómo la visión del matrimonio que tiene en cuenta lo justo debe informar la vida conyugal y familiar, siendo base necesaria de una fidelidad fecunda, y apoyo necesario para encarar y superar las crisis matrimoniales. Me gustaría también hacer ver que toda la pastoral familiar, incluso la que toca situaciones más afectadas por la fragilidad ${ }^{25}$, depende de una captación de la dimensión de justicia en el matrimonio indisoluble. Y aspiraría a extender esta consideración a los procesos matrimoniales, y en realidad a todo el derecho y la vida familiar, también en el ámbito civil, en el que valen los mismos criterios fundandos en la antropología jurídica de la sexualidad en el orden natural. Como es fácil advertir, todo esto nos llevaría demasiado lejos: prefiero por eso concluir sosteniendo que nada hay más práctico en la esfera del derecho que una comprensión adecuada de las realidades jurídicas, sobre todo si la relacionalidad interpersonal que les es propia es de índole natural. El matrimonio posee hasta tal extremo esa relacionalidad natural, que Dios mediante la Encarnación de su Hijo ha querido constituirlo signo y fuente eficaz del amor divino que dona a los esposos que de veras se quieren humanamente.

25 Remito a la nota que he escrito, Matrimonio y justicia objetiva en la comunión eclesial: un aspecto del discernimiento pastoral propiciado por Amoris laetitia, Ius Canonicum 56 (2016) 731-738. 


\section{Bibliografía}

Álvarez de las Asturias, N. - Parma, M. - Conde, J. C. - Marti, F., Studi sul favor fidei, Ius Ecclesiae 26 (2014) 311-378.

BAÑARES, J. I., La dimensión conyugal de la persona: de la antropología al derecho, Rialp, Madrid 2005.

Bernárdez CANTón, A. - García BARberena, T. (eds.), El vínculo matrimonial: ¿divorcio o indisolubilidad?, BAC, Madrid 22015.

Crouzel, H., Divorziati «risposati». La prassi della Chiesa primitiva (original francés: 1971), Cantagalli, Siena 2014.

D'Agostino, F., Filosofía de la familia, trad. cast., Rialp-Instituto de Ciencias para la Familia-Universidad de Navarra, Madrid-Pamplona 2006.

Donati, P., Manual de sociología de la familia, trad. cast., Eunsa, Pamplona 2003.

Errázuriz M., C. J., Matrimonio y justicia objetiva en la comunión eclesial: un aspecto del discernimiento pastoral propiciado por Amoris laetitia, Ius Canonicum 56 (2016) 731-738.

FrANCESCHI, H., La indisolubilidad del matrimonio. ¿Por qué para siempre?, en C. Mendoza (ed.), Perspectivas de cultura cristiana, Il pozzo di Giacobbe, Trapani 2014, 89-114.

GARCÍA HERVÁs, D., La disolución del matrimonio «in favorem fidei»: elementos para una investigación, Pontificia Universidad de Salamanca, Salamanca 2008.

Hervada, J., Una caro. Escritos sobre el matrimonio, Eunsa-Instituto de Ciencias para la Familia, Pamplona 2000.

PÉREZ-Soba, J. J., El amor crea vínculos: un anuncio liberador, Revista Española de Teología 75 (2015) 141-171.

PUIG, F., La esencia del matrimonio a la luz del realismo jurídico, Navarra Gráfica Ediciones, Pamplona 2004.

SEDANO, J., Las incertidumbres históricas sobre la potestad pontificia de disolver un matrimonio rato y no consumado: una clave interpretativa de la formación del vinculo matrimonial, Ius Canonicum 56 (2016) 229-269.

VILADRICH, P.-J., I fondamenti antropologici dell'indissolubilità del matrimonio, en H. FranCESCHI (ed.), Matrimonio e famiglia. La questione antropologica, EDUSC, Roma 2015, 143-216. 